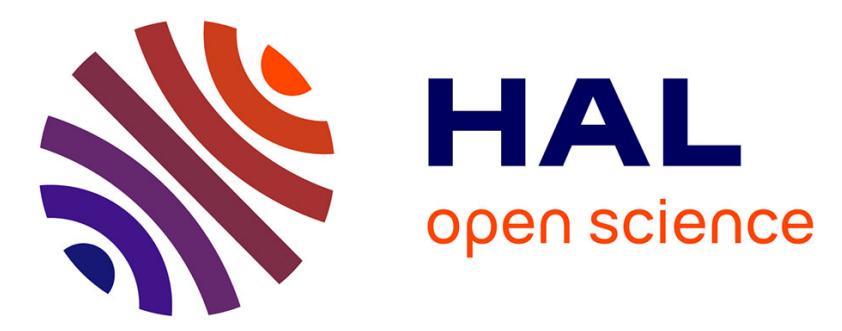

\title{
Tetrathiafulvalene-Tetracyanoquinodimethane Charge-Transfer Complexes Wired to Carbon Surfaces: Tuning of the Degree of Charge Transfer
} Joanna Jalkh, Yann Leroux, Antoine Vacher, Dominique Lorcy, Philippe Hapiot, Corinne Lagrost

\section{To cite this version:}

Joanna Jalkh, Yann Leroux, Antoine Vacher, Dominique Lorcy, Philippe Hapiot, et al.. Tetrathiafulvalene-Tetracyanoquinodimethane Charge-Transfer Complexes Wired to Carbon Surfaces: Tuning of the Degree of Charge Transfer. Journal of Physical Chemistry C, 2016, 120 (49), pp.2802128030. 10.1021/acs.jpcc.6b09459 . hal-01438122

HAL Id: hal-01438122

https://hal-univ-rennes1.archives-ouvertes.fr/hal-01438122

Submitted on 10 Apr 2017

HAL is a multi-disciplinary open access archive for the deposit and dissemination of scientific research documents, whether they are published or not. The documents may come from teaching and research institutions in France or abroad, or from public or private research centers.
L'archive ouverte pluridisciplinaire HAL, est destinée au dépôt et à la diffusion de documents scientifiques de niveau recherche, publiés ou non, émanant des établissements d'enseignement et de recherche français ou étrangers, des laboratoires publics ou privés. 


\section{Article}

\section{Tetrathiafluvalene-Tetracyanoquinodimethane Charge-Transfer Complexes Wired to Carbon Surfaces: Tuning of the Degree of Charge Transfer.}

Joanna Jalkh, Yann R Leroux, Antoine Vacher, Dominique Marie Lorcy, Philippe Hapiot, and Corinne Lagrost

J. Phys. Chem. C, Just Accepted Manuscript • DOI: 10.1021/acs.jpcc.6b09459 • Publication Date (Web): 14 Nov 2016

Downloaded from http://pubs.acs.org on November 15, 2016

\section{Just Accepted}

"Just Accepted" manuscripts have been peer-reviewed and accepted for publication. They are posted online prior to technical editing, formatting for publication and author proofing. The American Chemical Society provides "Just Accepted" as a free service to the research community to expedite the dissemination of scientific material as soon as possible after acceptance. "Just Accepted" manuscripts appear in full in PDF format accompanied by an HTML abstract. "Just Accepted" manuscripts have been fully peer reviewed, but should not be considered the official version of record. They are accessible to all readers and citable by the Digital Object Identifier (DOI®). "Just Accepted" is an optional service offered to authors. Therefore, the "Just Accepted" Web site may not include all articles that will be published in the journal. After a manuscript is technically edited and formatted, it will be removed from the "Just Accepted" Web site and published as an ASAP article. Note that technical editing may introduce minor changes to the manuscript text and/or graphics which could affect content, and all legal disclaimers and ethical guidelines that apply to the journal pertain. ACS cannot be held responsible for errors or consequences arising from the use of information contained in these "Just Accepted" manuscripts. 
Tetrathiafluvalene-Tetracyanoquinodimethane Charge-Transfer

Complexes Wired to Carbon Surfaces: Tuning of the Degree of Charge

\section{Transfer}

Joanna Jalkh, Yann R. Leroux, Antoine Vacher, Dominique Lorcy, Philippe Hapiot, and

Corinne Lagrost*

Institut des Sciences Chimiques de Rennes, Equipe MaCSE, CNRS and Université de Rennes

1, UMR $n^{\circ}$ 6226, Campus de Beaulieu, 35042 Rennes Cedex, France. 


\begin{abstract}
Charge-transfer complexes involving TTF (tetrathiafulvalene) and TCNQ (tetracyanoquinodimethane) derivatives are engineered in a $2 \mathrm{D}$ arrangement onto a carbon surface through the exposure of immobilized TTF units to TCNQ compounds. TTF molecules were immobilized as robust monolayers on carbon surfaces using the electrografting method followed by a click chemistry coupling. When the TTF monolayer is exposed to TCNQ, TCNQF 2 (2,5 difluoro-TCNQ) and $\mathrm{TCNQF}_{4}(2,3,5,6$ tetrafluoro-TCNQ), strong donoracceptor complexes are formed onto the surface. A considerable decrease of the electrochemical response accompanies the formation of the charge transfer complex. This observation is rationalized by the analysis of original crystal samples using an ultramicroelectrode cavity, confirming that charge-transfer complexes are electrochemically silent. A fine control of the degree of charge transfer with the judicious choice of different acceptors is evidenced through electrochemical and XPS measurements. Thus, donor-acceptor complexes of different nature are formed. A fully ionic charge-transfer complex is formed upon exposure of the TTF monolayer to the more oxidizing $\mathrm{TCNQF}_{4}$, while a neutral complex is obtained after exposure to the less oxidizing TCNQ. Exposition of the TTF monolayers to the intermediate $\mathrm{TCNQF}_{2}$ yields a mixture of neutral-ionic systems. These donor-acceptor interactions that fully mimic those described in the solid-state are rarely described in such a 2D arrangement, with systems being directly wired to an electrode.
\end{abstract}




\section{INTRODUCTION}

Organic charge transfer complexes are a class of molecular conductors that have been widely studied for their conducting and magnetic properties. ${ }^{1,2,3,4,5,6,7}$ The charge-transfer behavior between an electron donor and an electron acceptor is generally investigated in $3 \mathrm{D}$ solidphase systems, either organic crystals ${ }^{1,3,4,5}$ or more recently at the interface between two crystals $^{8,9}$ or between a powder in contact with a single crystal. ${ }^{10}$ Charge-transfer complexes could be also processed as Langmuir-Blodgett films, where the donor-acceptor organization allows the formation of high quality monolayers films with appealing conducting and magnetic properties. ${ }^{11}$ As illustrative example, a covalent TTF(tetrathiafulvalene)TCNQ(tetracyanoquinodimethane) diad exhibits an extremely low HOMO-LUMO gap, leading to facile electron transfer with five stable redox states. ${ }^{12}$ More rarely, these systems have been engineered as self-assembled monolayers (SAMs), ${ }^{13,14,15,16,17,18,19,20}$ despite the great interest of the strategy for realizing integrated devices. Indeed, SAMs would permit to organize charge-transfer complexes in an optimized 2D film structure, hence promoting cooperative properties. As donor molecules, TTF and its derivatives are almost ubiquitous in the field because of a good chemical stability, an accessible synthesis of the building blocks and their remarkable donor properties. ${ }^{1}$ The electron rich TTF molecules (and derivatives) could efficiently associate to electron-deficient acceptors like TCNQ derivatives to form charge transfer complexes. ${ }^{1}$ These complexes have remarkable electronic properties that can serve to build high electrically conductive system ${ }^{21}$ or molecular rectifier. ${ }^{22,23}$

Yet, a key question is to know how the special properties of TTF in solution or of TTFbased crystal solids are transferred to surface-confined species. ${ }^{24}$ In this context, the formation of a donor-acceptor complex was examined for SAMs of TTF alkylthiols chemisorbed on gold surfaces in presence of different acceptors like TCNQ. ${ }^{13,15,16}$ However, cyclic 
voltammetry analyses have revealed a puzzling behavior of these SAMs since the immobilized TTFs lost their electroactivity after exposure to TCNQ. ${ }^{16}$ A clear decrease of the oxidation current upon addition of TCNQ was reported. Authors concluded that only "free" TTFs, i.e. TTFs that were not involved in the donor-acceptor interactions, could contribute to a detectable electrochemical response but the origin of the phenomenon remained unclear. Note that the formation of a charge-transfer complex between TTF derivatives and $\mathrm{TCNQF}_{4}$, evidenced by micro-Raman spectroscopy, has led to a comparable decrease of the current response in presence of the acceptor but by using an ITO substrate. ${ }^{25}$ The main difficulties for understanding these observations are the relative fragility of SAMs on gold and the dynamic nature of the layer that could easily reorganize when a functional group or other bulky constraints are introduced on the layer. For example, it is common to substitute an alkylfunctionality in a prepared SAM by simply soaking the modified surface in a solution containing a different alkyl-thiol. ${ }^{26}$

Among possible surfaces for immobilizing a redox molecule, carbon materials are substrates of choice because they could be functionalized through a covalent link between the molecule and the substrate, allowing a particularly robust immobilization of the molecule. ${ }^{27}$ Carbon substrates present also interests for preparing materials with new properties as recently exemplified with the modification of graphene layers by TTF derivatives. ${ }^{28}$ The electrografting of aryldiazonium salts is a convenient approach for modifying carbon surfaces. The modification is based on the electrochemical production of transient reactive phenyl radicals at the vicinity of the carbon electrode surface that are able to attach on the carbon materials. ${ }^{27}$ To control the structure and the vertical extension of the layer, we have recently proposed a two-step method based on a bulky protected precursor, 4((triisopropylsilyl)ethynyl) benzenediazonium tetrafluoroborate (TIPS-Eth- $\left.\mathrm{ArN}_{2}{ }^{+}\right) \cdot{ }^{29}$ After removal of the TIPS group, a dense reactive ethynyl-terminated monolayer is obtained and 
could be post-functionalized by using the $\mathrm{Cu}(\mathrm{I})$-catalyzed Huisgen 1,3-dipolar cycloaddition with a variety of organic molecules containing an azido group. Interestingly, the distance between functional groups is controlled by the size of the leaving protecting group. ${ }^{30}$ In this work, we took benefit of this strategy for preparing well-organized, covalently attached TTF monolayers bridged with alkyl chain of different length (propyl, pentyl and decyl, i.e. $\mathrm{C}_{3}, \mathrm{C}_{5}$ and $\mathrm{C}_{10}$, respectively) on a carbon surface. Their charge transfer properties were carefully investigated upon exposure to a family of acceptors of increasing strength, TCNQ, TCNQF 2 and $\mathrm{TCNQF}_{4}$, by combining cyclic voltammetry, measurements with cavity ultramicroelectrode (UMEC) and X-ray photoelectron spectroscopy (XPS). Remarkably, our results evidence the formation of charge transfer complexes of different nature at the interface as function of the acceptors strength.

\section{EXPERIMENTAL SECTION}

Chemicals. Unless specified, all compounds were commercially available reagents and were used as received. Tetrabutylammonium hexafluorophosphate $\left(\mathrm{TBAPF}_{6}\right)$ of electrochemical grade was purchased from Aldrich. 4-((triisopropylsilyl)ethynyl) benzenediazonium tetrafluoroborate (TIPS-Eth- $\mathrm{ArN}_{2}{ }^{+}$) was prepared according to a previously described procedure. ${ }^{31} \mathrm{TCNQF}_{4}$ (2,5-difluoro-TCNQ) was prepared according to a published procedure. ${ }^{32}$ The synthesis of the azido TTFs with different alkyl chains was realized starting from the corresponding iodo-alkyl-TTF according to published procedures (see supporting information). ${ }^{33}$

Electrochemical Measurements. Electrochemical modification and characterization were performed with an Autolab PGSTAT N302 potentiostat/galvanostat (EcoChemie B.V.) equipped with the GPES software. A conventional three-electrode system, comprising a $3 \mathrm{~mm}$ 
diameter glassy carbon electrode as a working electrode, a platinum wire as the auxiliary electrode, and a SCE electrode as reference, was used. The surface concentration of active TTF centers were derived from the faradaic charge of the first monoelectronic oxidation according to the following equation $\Gamma=Q / F A$, where $F$ is the Faraday constant, $A$ is the surface of the glassy carbon electrode, $Q$ the charge obtained from the integration of the area under the voltammetric peak.

For UMEC analyses, ${ }^{34}$ the ultramicroelectrode was provided through the "UMEC Network of CNRS". ${ }^{35}$ The microcavity of the ultra-microelectrode (approximately $17 \mu \mathrm{m}$ diameter cavity) was filled with a homogeneous mixture of the crystal under study and graphite powder in a 4:1 ratio. The voltammograms were recorded using a $1: 1 \mathrm{v} / \mathrm{v}$ ethanol/water solution containing $0.1 \mathrm{~mol} \mathrm{~L}^{-1} \mathrm{KPF}_{6}$ as electrolyte at a scan rate of $10 \mathrm{mV} \mathrm{s}^{-1}$.

Electrode Modification. The electrochemical procedure used for the modification of the carbon electrodes (glassy carbon disk or pyrolized photoresist films (PPF) substrates) is presented in Scheme 1 and is based on the method described in reference 29. Briefly, the first step was the electrografting of the protected TIPS-Eth- $\mathrm{ArN}_{2}{ }^{+}$onto the carbon electrode from an acetonitrile solution containing $10^{-2} \mathrm{~mol} \mathrm{~L}^{-1}$ TIPS-Eth- $\mathrm{ArN}_{2}{ }^{+}$and $10^{-1} \mathrm{~mol} \mathrm{~L}^{-1} \mathrm{TBAPF}_{6}$ and using 5 cycles between 0.6 and $-0.75 \mathrm{~V}$ (vs SCE) at a scan rate of $50 \mathrm{mV} \mathrm{s}^{-1}$. The modified surfaces were then rinsed with acetone and stirred in THF for $20 \mathrm{~min}$. TIPS deprotection was performed by immersing the modified electrodes in a stirred solution of $10^{-1} \mathrm{~mol} \mathrm{~L}^{-1} \mathrm{TBAF}$ (tetrabutylammonium fluoride) in THF for $20 \mathrm{~min}$. $\mathrm{N}_{3}-\mathrm{C}_{\mathrm{n}}$-TTF molecules were then coupled to the resulting $\mathrm{H}$-Eth monolayers by a Huisgen 1,3-dipolar cycloaddition (click chemistry). For that, the H-Eth modified electrodes were immersed in a stirred $5 \mathrm{~mL}$ solution of TTF$\left(\mathrm{CH}_{2}\right)_{\mathrm{n}}-\mathrm{N}_{3}(\mathrm{n}=3,5,10)(1 \mathrm{mg})$ in THF and $\mathrm{CuSO}_{4}\left(2.5 \mathrm{~mL}, 10^{-2} \mathrm{~mol} \mathrm{~L}{ }^{-1}\right)$ was added. After degassing the solution for 15 min under argon, $\mathrm{L}(+)$-ascorbic acid $\left(10^{-2} \mathrm{~mol} \mathrm{~L}^{-1}\right.$ in $2.5 \mathrm{~mL}$ water containing $80 \mathrm{mg}$ of $\mathrm{NaHCO}_{3}$ ) was added dropwise to the solution. The reaction 
mixture was left stirring under argon for $1 \mathrm{hr}$. The resulting electrodes were then stirred in a saturated EDTA solution for 10 min to remove any residual copper.

X-Ray Photoelectron Spectroscopy Measurements. X-ray photoelectron spectroscopy data have been collected using a Kratos Axis Nova spectrometer using the Al Ka X-ray source working at $1486.6 \mathrm{eV}$ and using a spot size of $0.7 \times 0.3 \mathrm{~mm}^{2}$. Survey spectra $(0-1000$ $\mathrm{eV})$ were acquired with an analyzer pass energy of $80 \mathrm{eV}(0.5 \mathrm{eV} / \mathrm{step})$; high-resolution spectra used a pass energy of $20 \mathrm{eV}(0.1 \mathrm{eV} / \mathrm{step})$. Binding energies were referenced to $\mathrm{C} 1 \mathrm{~s}$ peak at $285 \mathrm{eV}$. The atomic percentage for surface composition was estimated using the integrated peak areas in the survey spectra; the peak areas were normalized by the manufacturer-supplied sensitivity factor. The core level spectra were peak-fitted using the CasaXPS software, Ltd., version 2.3.17).

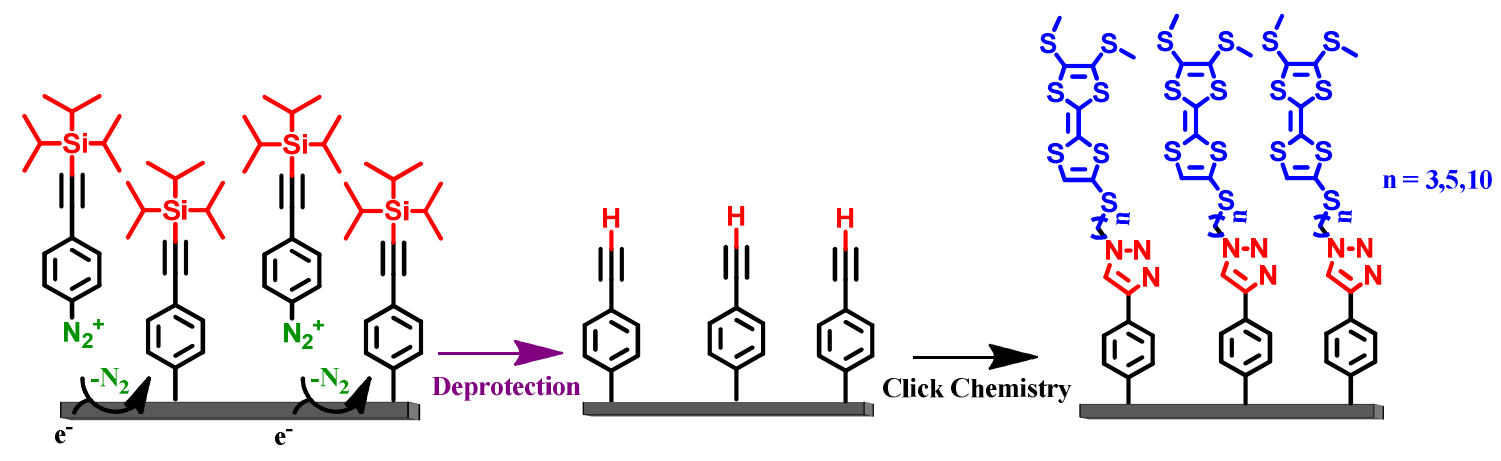

Scheme 1. Functionalization of carbon surfaces by TTF-terminated monolayers

\section{RESULTS AND DISCUSSION}

\section{Redox Behavior of a Glassy Carbon Electrode Modified with the alkyl-TTF layers.}

Three TTF derivatives with different alkyl-chain linkers (propyl $\left(\mathrm{C}_{3}\right)$, pentyl $\left(\mathrm{C}_{5}\right)$ and decyl $\left.\left(C_{10}\right)\right)$ were immobilized on the carbon surface following a previously published procedure as 
depicted in Scheme 1. ${ }^{29}$ The $\mathrm{C}_{\mathrm{n}}$-TTFs functionalized with azide groups were coupled to the reactive ethynyl monolayer by "click chemistry". Figure 1 shows the cyclic voltammetry in dichloromethane containing $0.2 \mathrm{~mol} \mathrm{~L}^{-1} \mathrm{TBAPF}_{6}$ recorded after copious rinsing of the modified electrodes. For the three layers, two successive well-defined redox processes are observed and are characteristic to the reversible oxidation of the TTFs to their cations and to their dications, respectively (Table 1$).{ }^{1}$ For the three modified surfaces, the intensity of the peak currents varies linearly as a function of the scan rates as expected for a surface-confined redox couple. ${ }^{36}$ Moreover, the TTF layers present good electrochemical stability upon cycling, the cyclic voltammetry experiments could be repeated more than 10 times without any significant variation (See Figure S1 in the supplementary section). By integration of the faradaic oxidation current, surface concentrations were estimated to $5( \pm 2) \times 10^{-10} \mathrm{~mol} . \mathrm{cm}^{-2}$ based on repeated measurements. Considering the roughness of a glassy carbon electrode (typically the roughness factor is $2-2.5$ for a carefully polished electrode) ${ }^{30}$ this value confirms that relatively dense monolayers of TTF are obtained. The surface concentration of an ideal close-packed monolayer of TTF was reported to be $3.6 \times 10^{-10} \mathrm{~mol} \mathrm{~cm}{ }^{-2} \cdot{ }^{13}$ However in our case, the maximum packing of the TTF units is imposed by the steric hindrance of the TIPS protective group, hence leading to a surface concentration equal to $2.3 \times 10^{-10} \mathrm{~mol} \mathrm{~cm}^{-2}$ for an ideal hexagonal compact arrangement. ${ }^{30}$ The experimental value found is in a fairly good agreement with this theoretical value. The overall shape of the cyclic voltammetry differs from those previously reported for the oxidation of alkylthiol-TTF monolayers on gold (SAM). ${ }^{26,38,24}$ While the chemical stability and redox activity of the TTF are generally kept after immobilization in SAMs, ${ }^{26,37}$ their electrochemical characteristics are considerably modified. Notably, the peak shapes and widths are affected, depending on the oxidation states of TTF, on the organization of the TTF units in the layer and on the electrolyte media. ${ }^{26,38}$ These effects were ascribed to the interactions between the TTF moieties, and could be easily 
identified by cyclic voltammetry. ${ }^{26}$ Published studies have reported voltammograms with a first dissymmetric wide peak (full width at half maximum, FWHM, around 160-170 mV) and a much narrower second one (FWHM of 50-60 mV). ${ }^{26,38,24}$ These observations were explained by strong intermolecular interaction taking place within the monolayers upon the charging process. ${ }^{26,39}$ The small FWHM values for the second process (much narrower than the ideal 90 $\mathrm{mV}$ expected for non-interacting redox centers) have been ascribed to strong attractive interactions between the $\mathrm{TTF}^{2+}$ centers. ${ }^{26,39}$

Table 1. Electrochemical Data from Cyclic Voltammetry for the Oxidation of Monolayers of TTF- $C_{n}(n=3,5,10)^{a}$ in $\mathrm{CH}_{2} \mathrm{Cl}_{2}$ Containing 0.2 mol ${ }^{-1} \mathrm{TBAPF}_{6}$.

$\begin{array}{cccc}\text { Monolayers } & \text { At } 0.2 \mathrm{Vs}^{-1} & \text { Redox process \#1 } & \text { Redox process \#2 } \\ \text { TTF-C }_{3} & \mathrm{E}^{\circ}(\mathrm{V} \text { vs SCE }) & 0.50 & 0.83 \\ & F W H M(m V) & 178 & 126 \\ \text { TTF-C }_{5} & \mathrm{E}^{\circ}(\mathrm{V} \text { vs SCE }) & 0.49 & 0.82 \\ & F W H M(m V) & 176 & 124 \\ \text { TTF-C }_{10} & \mathrm{E}^{\circ}(\mathrm{V} \text { vs SCE }) & 0.50 & 0.84 \\ & F W H M(m V) & 186 & 122\end{array}$

${ }^{\mathrm{a}} \mathrm{All}$ the monolayers exhibit close surface concentrations

In our experiments, the second redox peak is also narrower than the first one, but shapes of the two processes are more comparable, with FWHM larger than those reported for the TTF SAMs on gold. All these observations correspond to weaker interactions between the TTF moieties. It is likely that the covalent grafting of our arylethynyl platform limits the reorganization and packing in the TTF monolayers. ${ }^{30}$ The steric hindrance of the bulky protective TIPS group controls the distance between the anchorage sites of the TTF units and leaves space between them resulting in a sort of frozen arrangement. ${ }^{30}$ This would allow an easier solvation process/counter-ion penetration in the monolayers, decreasing the strength of attraction between the $\mathrm{TTF}^{2+}$ units. Additionally, a shoulder-like system is observed at the second oxidation peak (located at the more positive potentials side) for the TTF linked 
through the longest alkyl chains (TTF- $\mathrm{C}_{5}$ and TTF- $\mathrm{C}_{10}$ ) (Figure 1). This "extra" peak is even more visible for the TTF with the longest alkyl chain linker $\left(\mathrm{C}_{10}\right)$. The splitting of the oxidation/reduction peaks suggests the co-existence of "isolated" (lower potential) and "clustered" (higher potential) $\mathrm{TTF}^{2+}$ species, the formation of "clustered" species being facilitated by the flexibility introduced by longer alkyl chains as observed for alkyl-ferrocene layer. $^{40}$

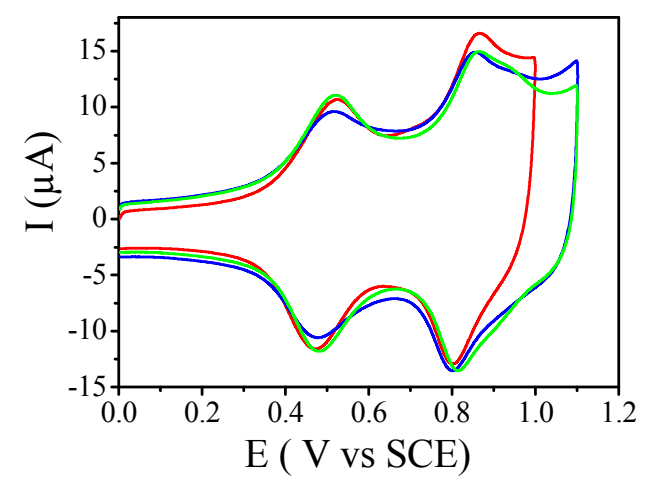

Figure 1. Cyclic voltammograms recorded in dichloromethane $\left(+0.2 \mathrm{~mol} \mathrm{~L}^{-1} \mathrm{TBAPF}_{6}\right)$ of TTF-terminated monolayers having bridging units of different chain lengths $\left(\mathrm{C}_{3}\right.$ (red) $\mathrm{C}_{5}$ (blue) and $\mathrm{C}_{10}$ (green)) at a glassy carbon electrode. Scan rate $=200 \mathrm{mV} \mathrm{s}^{-1}$.

\section{Acceptor-donor Complexes between TTF- $C_{n}$ Monolayers and TCNQ Derivatives.}

To examine the properties of charge-transfer complexes with the TTF layer on carbon, cyclic voltammograms of the TTF layers were recorded before and after immersion of the modified electrode in $\mathrm{CH}_{2} \mathrm{Cl}_{2}$ solutions of $\mathrm{TCNQ}, \mathrm{TCNQF}_{2}$ and $\mathrm{TCNQF}_{4}$ with increasing concentrations and after extensive rinsing with clean $\mathrm{CH}_{2} \mathrm{Cl}_{2}$. For the three layers, a considerable decrease of the oxidation peak currents is observed after exposure to the TCNQ derivatives solutions. Figure 2 shows some typical voltammograms obtained for the TTF- $\mathrm{C}_{10}$ layer. Under our experimental conditions, the current intensities decrease monotonically with the increase of acceptors concentration to reach a constant value when the TCNQs 
concentrations are above $2-4 \times 10^{-3} \mathrm{~mol} \mathrm{~L}^{-1}$. From the maximum current decrease, we could estimate that roughly 40 to $60 \%$ of the immobilized TTF units become electrochemically silent after exposure to the TCNQ derivatives solutions. The observation of the current drop is the least intense for the layer with the short linker, indicating that a more flexible layer favors the phenomenon. For example, using $\mathrm{TCNQF}_{4}$ as an acceptor, $40 \%$ of TTF units become electro-inactive for the TTF-C 3 layer after immersion in the acceptor solution while more than $55 \%$ for $\mathrm{TTF}^{-\mathrm{C}_{5}}$ and TTF-C 10 are silent under the same conditions. In all cases, it was not possible to recover the initial electro-activity of the layer even after repeated cycling in a blank $\mathrm{CH}_{2} \mathrm{Cl}_{2}$ solution; the cyclic voltammograms of the TTF layer remain unchanged. Finally, as a test experiment, a comparable monolayer, but functionalized with undecylferrocene units, was exposed to the same $\mathrm{TCNQF}_{4}$ solutions. No modifications of the voltammograms were observed after exposure of the modified surface to $\mathrm{TCNQF}_{4}$ (Figure S2). All these observations indicate that the interactions between TTF and the TCNQ derivatives are strong and specific of the TTF layers. Importantly, this effect does not depend on the strength of the acceptor which can be quantified through its formal reduction potential. The di- and tetra-fluoro analogues of TCNQ exhibit more positive formal potentials than TCNQ, i.e. $\mathrm{E}^{\circ}=0.53 \mathrm{~V}$ vs SCE, $0.39 \mathrm{~V}$ vs $\mathrm{SCE}$ and $+0.17 \mathrm{~V}$ vs SCE for $\mathrm{TCNQF}_{4}, \mathrm{TCNQF}_{2}$ and TCNQ, respectively.
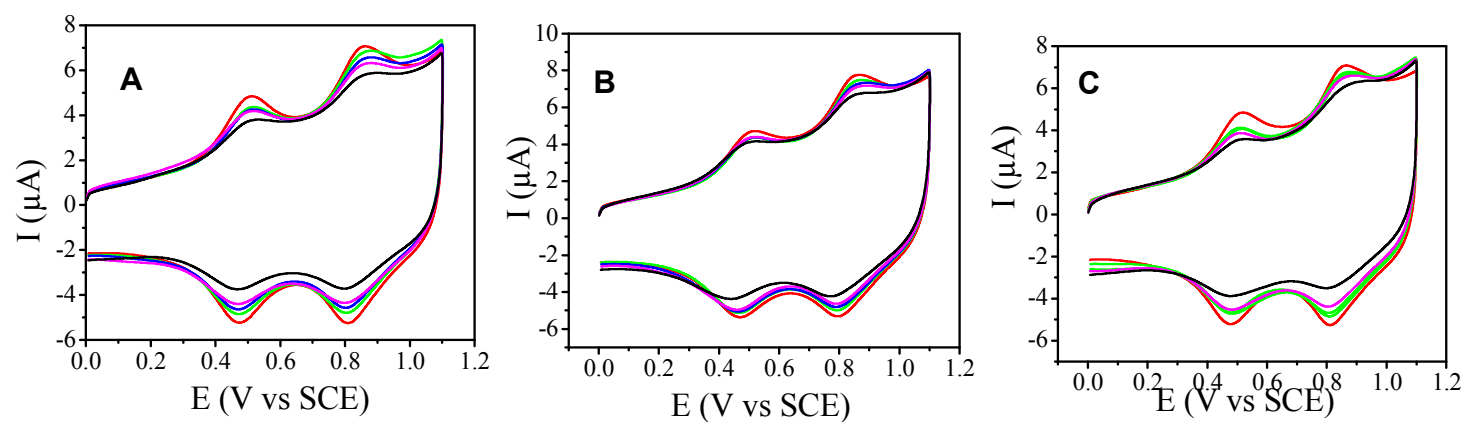

Figure 2. Cyclic voltammograms in dichloromethane $\left(+0.2 \mathrm{~mol} \mathrm{~L}^{-1} \mathrm{TBAPF}_{6}\right)$ of a glassy carbon electrode modified with the TTF- $\mathrm{C}_{10}$ monolayer, before (red curves) and after 
exposure to a solution with increasing concentrations of TCNQ derivatives (A) TCNQ, (B) $\mathrm{TCNQF}_{2},(\mathrm{C}) \mathrm{TCNQF}_{4}$ ). S1 $=10^{-4} \mathrm{~mol} \mathrm{~L}^{-1}$ (green), $\mathrm{S} 2=510^{-4} \mathrm{~mol} \mathrm{~L}^{-1}$ (blue), $\mathrm{S} 3=10^{-3} \mathrm{~mol}$ $\mathrm{L}^{-1}$ (magenta) and $\mathrm{S} 4=810^{-3} \mathrm{~mol} \mathrm{~L}^{-1}$ (black).

Similar current decreases were previously reported for self-assembled layer of thioalkyl TTFs onto a gold electrode surfaces in presence of acceptor molecules. ${ }^{16}$ Authors suggested that this current drop results from a donor-acceptor interaction between the TTF and the TCNQ.

To further support this hypothesis, a key question is about the expected electrochemical response of a charge transfer complex involving TTF and TCNQ derivatives. If these associations are commonly considered and described in the literature, ${ }^{1,5}$ there was no specific examinations about their electrochemical responses, particularly under a crystallized form that could be compared to a TTF layer. In that purpose, we prepared crystals of a charge transfer complex with $\operatorname{TTF}\left(\mathrm{E}^{\circ}=0.33 \mathrm{~V}\right.$ vs $\left.\mathrm{SCE}\right)$ and $\mathrm{TCNQF}_{2}\left(\mathrm{E}^{\circ}=0.39 \mathrm{~V}\right.$ vs $\left.\mathrm{SCE}\right)$. Note that, in this case, the reduction potential of the acceptor is larger than the oxidation potential of the donor, which could lead to a fully ionic charge transfer as in the case of the TTF- $\mathrm{C}_{\mathrm{n}}$ and $\mathrm{TCNQF}_{4}$. The electrochemical activity of these crystals was investigated by means of the ultramicroelectrode cavity (UMEC) technique. ${ }^{34,35}$ The UMEC technique allows the electrochemical analysis of a very small amount of powder materials and is particularly relevant for electrochemical analysis of crystals. The cavity of the ultramicroelectrode was filled with crystals of TTF-TCNQF 2 charge transfer complex. As comparative experiments, the electrochemical signals of the oxidation of TTF crystals filling the same cavity were also recorded (See Figure S4 for experiments with pure $\mathrm{TCNQF}_{2}$ crystals). 
The electrochemical measurement was performed in 1:1 (v/v) ethanol/water mixture containing $\left(+0.1 \mathrm{~mol} \mathrm{~L}^{-1}\right) \mathrm{KPF}_{6}$ as supporting salt to limit the dissolution of the crystal in the solution. As a remarkable feature, the electrochemical signals of the TTF oxidation (or of the $\mathrm{TCNQF}_{2}$ reduction) that are clearly detected in the pure TTF crystals, disappear in the TTF$\mathrm{TCNQF}_{2}$ charge-transfer crystal (Figure 3).
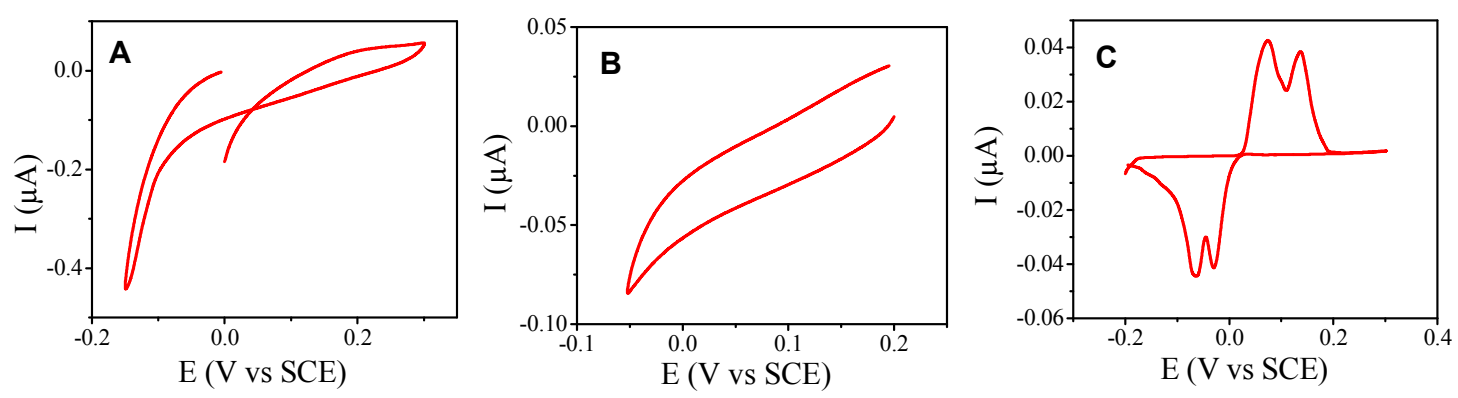

Figure 3. Cyclic voltammetry with an UMEC recorded in a $1: 1$ ethanol/water solution $(+0.1$ mol L ${ }^{-1} \mathrm{KPF}_{6}$ ). Scan rate $=10 \mathrm{mV} \mathrm{s}^{-1}$. (A) TTF-TCNQF 2 crystal observed in oxidation, (B) TTF-TCNQF 2 crystal observed in reduction. (C) For comparison, oxidation of a TTF crystal with same conditions showing the two successive reversible oxidation steps.

These observations confirm that the charge transfer complex displays no electroactivity in the potentials range where the oxidation of TTF is observed, clearly supporting the assumption that charge transfer between the immobilized TTF and the TCNQ derivatives suppress their electrochemical activity as described above. This absence of electroactivity of the complex could be due to the strong activation energy that would be required to break the TTF-TCNQF 2 association, making the oxidation of TTF more difficult. Indeed, a small signal around $0.2 \mathrm{~V}$ that could be ascribed to the TTF oxidation appears after scanning the potential scan with an expanded window (notably towards a more negative potentials excursion). Similar observations have been reported for TTF-TCNQ complexes as 
compacted pellets. ${ }^{41}$ Large overpotentials were required to observe the electrochemical signature of TTF and TCNQ. Therefore, the remaining electrochemical activity observed with the TTF monolayers, after exposure to TCNQ derivatives solution, is probably due to the TTF units, which are not involved in the donor/acceptor interactions.

The ratio $i_{p} / i_{p T T F}$ (where $i_{p}$ and $i_{p T T F}$ are the first oxidation peak currents recorded by cyclic voltammetry measured after and before immersion of the TTF- $\mathrm{C}_{\mathrm{n}}$ layer in the TCNQ derivative solution, respectively) could be considered to quantify the efficiciency of the formation of the donor-acceptor complexes in the layer. The smallest $i_{p} / i_{p T T F}$ corresponds to the strongest donor/acceptor interactions. It is noticeable that $i_{p} / i_{p T T F}$ depends both on the acceptor redox potential, $E_{T C N Q}^{\circ}$ and on linker length (Figure S9). For the shortest and less flexible layer (TTF-C 3 ), comparable $i_{p} / i_{\text {PTTF }}$ variations are observed for the three different acceptors with $i_{p} / i_{p T T F}$ around 0.6 (Figure S9). In contrast, for the more flexible TTF-C 10 layer, $i_{p} / i_{\text {PTTF }}$ varies considerably with the acceptor as the following trend: TCNQF $4(0.38)<\mathrm{TCNQ}$ $(0.5)<\mathrm{TCNQF}_{2}(0.7)$. If the most efficient complexation is indeed observed with $\mathrm{TCNQF}_{4}$ as acceptor, having the larger reduction potential, an inversion exists between TCNQ and $\mathrm{TCNQF}_{2}$ suggesting that the redox potential is probably not the only relevant parameter to quantify the strength of such interaction(vide infra).

To further confirm this puzzling behavior, the blocking properties towards electronic transfer of the TTF- $\mathrm{C}_{10}$ monolayers, before and after exposure to the different acceptors, were studied. In that purpose, we used a classical electrochemical probe, dopamine that was originally proposed by R. McCreery et al. Oxidation of dopamine to the corresponding orthoquinone requires the adsorption of dopamine onto the carbon electrode substrate for a fast charge transfer kinetics and the coating of the carbon electrode surface with a dense and compact monolayer was demonstrated to inhibit the oxidation of dopamine..$^{42,43,44}$ Thus, observation of electrochemical activity implies that dopamine is able to reach the electrode 
surface. Examination of the electrochemical response of dopamine oxidation provides evidence about the presence of pinholes in a monolayer and, consequently about its compactness on a carbon substrate. Figure 4 displays the voltammograms of the dopamine oxidation on a glassy carbon electrode modified with the TTF- $\mathrm{C}_{10}$ monolayer before and after exposure to the TCNQ derivatives.

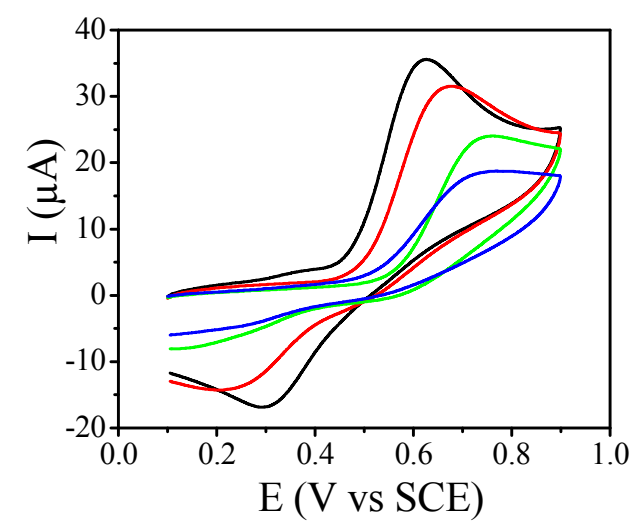

Figure 4. Cyclic voltammetry of $10^{-3} \mathrm{M}$ dopamine in $0.1 \mathrm{~mol} \mathrm{~L}^{-1} \mathrm{H}_{2} \mathrm{SO}_{4}$ solution on a GC electrode modified with TTF- $\mathrm{C}_{10}$ monolayers before (black) and after exposure to TCNQ derivatives, TTF-TCNQF 2 (red), TTF-TCNQ (green), and TTF-TCNQF 4 (blue). Scan rate = $0.1 \mathrm{~V} \mathrm{~s}^{-1}$.

A well-defined voltammogram is observed on carbon surfaces modified with TTF- $\mathrm{C}_{10}$ (before exposure to acceptors), indicating the presence of pathways allowing the passage of dopamine through the TTF layer. After exposure to TCNQ derivatives, the oxidation of dopamine remains visible, but the peak-to-peak potential separations increase, the peak currents display a larger plateau-shape and their intensity are lowered. These observations show that the passage of dopamine through the TTF layer becomes more difficult, corresponding to a more blocking character of the layer after exposure to a TCNQ derivative. ${ }^{45},{ }^{46}$ However, the magnitude of the variations in the dopamine oxidation signal are 
different according to the different acceptors (Figure 4). It is especially remarkable that the same trend is deduced from the ratios $i_{p} / i_{\text {pTTF }}$ that characterize the strength of the acceptordonor complexes and from the variations of the blocking character of the layer after exposure to the acceptor, i.e. TTF-TCNQF 4 - TTF-TCNQ $>$ TTF-TCNQF 2 . These results support the idea that intermolecular spaces between the TTF units exist within the monolayer (Figure 4, black line) and can be filled by the acceptors (Figure 4, green/red/blue lines). Indeed, considering that the molecular size of dopamine and TCNQ are comparable, the intermolecular space is large enough to permit the passage of TCNQ derivatives within the layer, promoting the formation of the charge transfer complexes. The TCNQ compounds that interact with the TTF layer literally close the intermolecular spaces and add rigidity in the structure of the monolayer, preventing dopamine from reaching the carbon surface. Depending on the strength of the donor-acceptor interactions, these spaces are more or less well blocked (Figure 5). Thus, $\mathrm{TCNQF}_{4}$ undergoes the most efficient charge transfer complexation and its interaction with the $\mathrm{TTF}-\mathrm{C}_{10}$ monolayer leads to the largest blocking of the carbon surface towards dopamine (Figure 4, blue line).

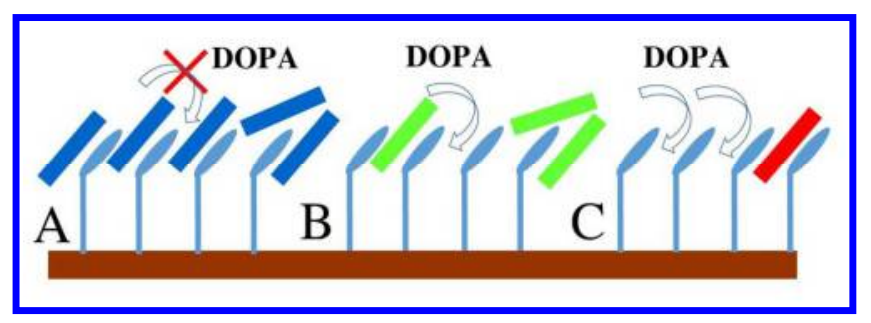

Figure 5. Schematic representation of the blocking properties towards dopamine (DOPA) of the TTF- $\mathrm{C}_{10}$ monolayer associated with A) $\mathrm{TCNQF}_{4}, \mathrm{~B}$ ) TCNQ and C) TCNQF 2

XPS Analyses of Donor-Acceptor Complex At TTF-C 10 Monolayers. PPF (Pyrolyzed Photoresist Film) substrates functionalized with TTF- $\mathrm{C}_{10}$ monolayers were analyzed by X-ray 
Photoelectron spectroscopy (XPS), before and after exposure to the TCNQ derivatives, to gain a deeper understanding of the nature of the donor-acceptor complexation. The survey spectra exhibit substantial changes after the exposure of the TTF- $\mathrm{C}_{10}$ monolayers to the TCNQ derivatives, indicating modifications in surface compositions (Figure S6). Intense C1s peaks are detected at $285 \mathrm{eV}$ due to the PPF substrate and to the TTF monolayers, whether complexed with TCNQ derivatives or not. N1s (at $400 \mathrm{eV}$ ) and S2p (at $164 \mathrm{eV}$ ) peaks that are fully characteristic to the organic monolayers are also observed. F1s peaks (at $688 \mathrm{eV}$ ) with significant atomic percentage could be identified for the TTF monolayers exposed to TCNQF 2 and $\mathrm{TCNQF}_{4}$. Accordingly, the fluorine atomic percentage is larger with $\mathrm{TCNQF}_{4}$ than with $\mathrm{TCNQF}_{2}$. Trace levels of fluorine $(<1 \%)$ are also detected in the survey scans of TTF- $\mathrm{C}_{10}$ monolayers and TTF- $\mathrm{C}_{10}$ monolayers exposed to TCNQ (Table 2) probably due to a contamination at the samples during the deprotection step in the monolayer preparation.

Table 2. Surface Composition (\% atom, $\pm 20 \%$ ) of TTF- $\mathrm{C}_{10}$ Monolayers before and after Exposure to TCNQ, TCNQF 2 or $\mathrm{TCNQF}_{4}$ Solutions

$\begin{array}{ccccc}\text { \% atom } & \text { TTF } & \text { TTF-TCNQ } & \text { TTF-TCNQF }_{2} & \text { TTF-TCNQF }_{4} \\ \% \mathrm{C} & 79.7 & 86.8 & 82.8 & 82.3 \\ \% \mathrm{~N} & 1.7 & 1.9 & 1.7 & 3.6 \\ \% \mathrm{~F} & 0.9 & 0.6 & 2.9 & 3.5 \\ \% \mathrm{~S} & 4.5 & 2.9 & 3.2 & 3.0 \\ \% \mathrm{O} & 13.2 & 7.8 & 9.4 & 7.6\end{array}$

The N1s core level spectra could be decomposed into several components that take into account the triazole groups (i.e. two peaks at $399.9 \mathrm{eV}( \pm 0.5)(\underline{\mathbf{N}}-\mathrm{N}=\mathrm{N})$ and at $401.1( \pm$ 0.5) $\mathrm{eV}(\mathrm{N}-\underline{\mathbf{N}}=\mathbf{N})$, with a ratio of $1: 2)^{47}$ for the TTF- $\mathrm{C}_{10}$ monolayers and the TCNQ derivatives for the exposed monolayers (Figure 6). An important feature is the appearance of a shoulder-like peak at lower binding energy $(398.5( \pm 0.5) \mathrm{eV})$ for the monolayers exposed to $\mathrm{TCNQF}_{2}$ and $\mathrm{TCNQF}_{4}$ (Figure 6). This could be ascribed to the presence of negatively 
charged $\mathrm{TCNQF}_{2}$ or $\mathrm{TCNQF}_{4}$ molecules. ${ }^{48}$ The low binding energy contribution is more pronounced for the monolayers exposed to $\mathrm{TCNQF}_{4}$, indicating that the monolayers are complexed with larger amount of negatively charged species. In sharp contrast, the TTF- $\mathrm{C}_{10}$ monolayers exposed to TCNQ do not show this contribution and the decomposition gives a component at $400.4( \pm 0.5) \mathrm{eV}$ that is attributed to neutral TCNQ species (Figure 6). ${ }^{48}$ This component also contributes to the N1s signal of TTF- $\mathrm{C}_{10}$ monolayer exposed to TCNQF 2 while being only a minor component for TTF- $\mathrm{C}_{10}$ monolayer exposed to TCNQF 4 .
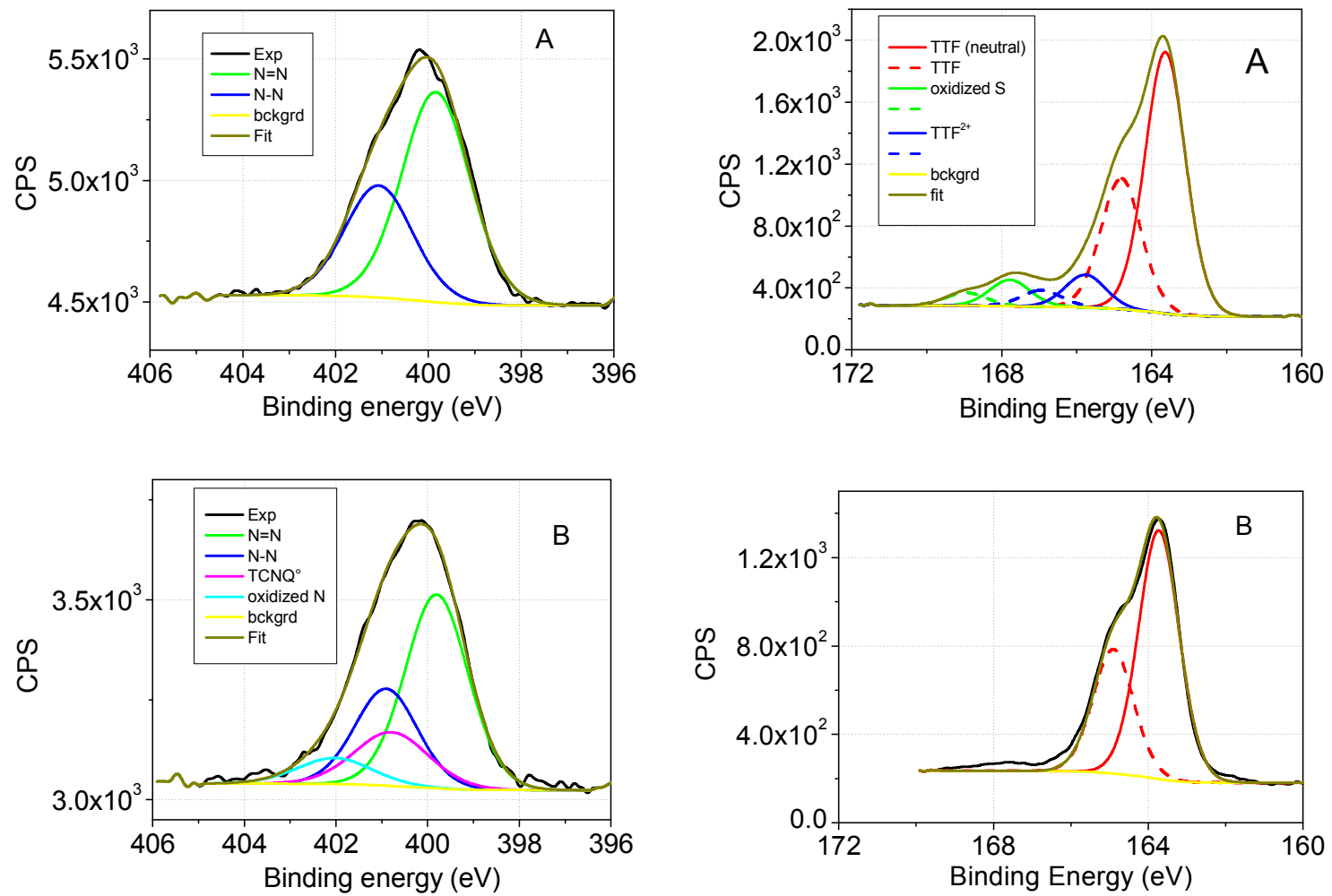

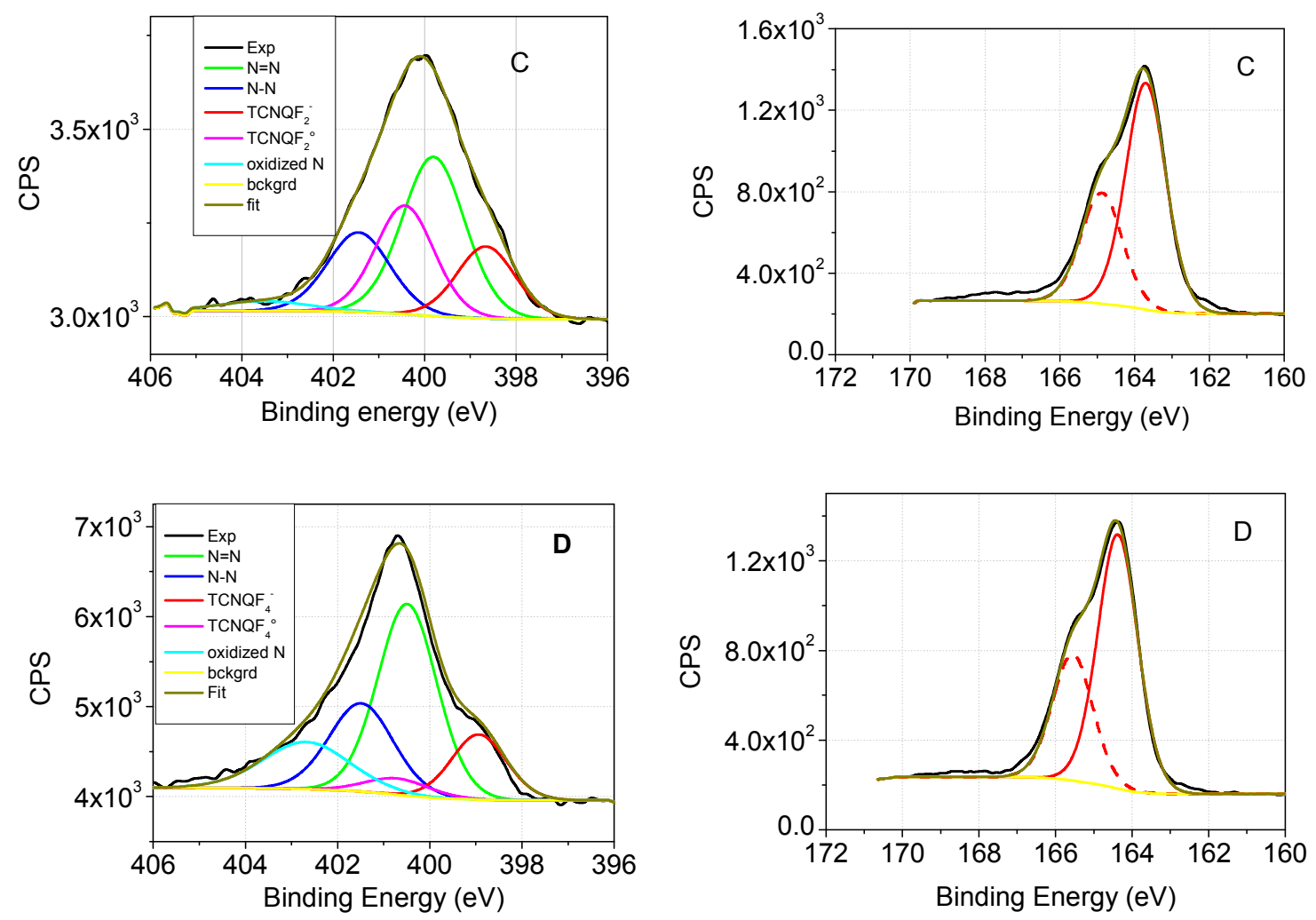

Figure 6. Peak-fitted high resolution core level spectra of N1s (left) and S2p (right) for PPF modified by TTF- $\mathrm{C}_{10}$ monolayer, before (A) and after exposure to TCNQ (B), $\mathrm{TCNQF}_{2}(\mathrm{C})$ and $\mathrm{TCNQF}_{4}(\mathrm{D})$, respectively.

It is further interesting to focus on the signal corresponding to $\mathrm{S} 2 \mathrm{p}$ for the four different samples. In all cases, the experimental signal exhibits the expected doublet structure due to spin orbit splitting that leads to $\mathrm{S} 2 \mathrm{p}_{3 / 2}$ and $\mathrm{S} 2 \mathrm{p}_{1 / 2}$ peaks (Figure 6). For the TTF-C 10 monolayers unexposed and exposed to TCNQ and $\mathrm{TCNQF}_{2}$, the main doublet at $163.6( \pm 0.5)$ $\mathrm{eV}\left(\mathrm{S} 2 \mathrm{p}_{3 / 2}\right)$ and $164.8( \pm 0.5) \mathrm{eV}\left(\mathrm{S} 2 \mathrm{p}_{1 / 2}\right)$ could be ascribed to the neutral TTF units (Figure 6). ${ }^{49}$ Interestingly, the TTF- $\mathrm{C}_{10}$ monolayers exposed to $\mathrm{TCNQF}_{4}$, lead to a $\mathrm{S} 2 \mathrm{p}$ doublet signal at $164.4( \pm 0.5) \mathrm{eV}\left(\mathrm{S} 2 \mathrm{p}_{3 / 2}\right)$ and at $165.6( \pm 0.5) \mathrm{eV}\left(\mathrm{S} 2 \mathrm{p}_{1 / 2}\right)$, hence significantly shifted to higher binding energy (Figure 6). This result agrees well with the reported position of 
positively charged TTF molecules $\left(\mathrm{TTF}^{+}\right),{ }^{49,50}$ indicating that the TTF units are oxidized when exposed to $\mathrm{TCNQF}_{4}$. The presence of negatively charged $\mathrm{TCNQF}_{4}$ as evidenced in the N1s signal establishes that $\mathrm{TCNQF}_{4}$ molecules symmetrically act as electron acceptor, showing the full charge transfer process between the immobilized TTF units and TCNQF 4 . Contrariwise, the XPS analyses indicate that the immobilized TTF units form neutral donoracceptor complexes with TCNQ. A less clear-cut phenomenon could be deduced from the XPS studies in the case of $\mathrm{TCNQF}_{2}$, because of the presence of a mixture of neutral and fully ionic charge-transfer complexes at the PPF surfaces. Remarkably, these behaviors are fully similar to those described in the solid-state. In the solid-state, depending on the oxidation potential value of the donor relatively to the reduction potential of the acceptor, complexes of different natures could be isolated: for instance, neutral charge-transfer complex if the potentials difference between acceptor and donor is less than $-350 \mathrm{mV}$, while neutral-ionic transitions could be observed for potentials difference between 0 and $-350 \mathrm{mV} .{ }^{51,52}$ A fully ionic charge-transfer complex could form if the reduction potential of the acceptor is higher than the oxidation potential of the donor, leading to the formation of a salt with a ionicity degree equal to $1 .^{53,54}$ In our work, the formation of a fully ionic charge-transfer complex could happen only with the $\mathrm{TCNQF}_{4}$ acceptor, by considering the oxidation potential of the immobilized TTF units relatively to the reduction potential of $\mathrm{TCNQF}_{4}$. Likewise, exposure of the TTF- $\mathrm{C}_{10}$ monolayers to TCNQ could yield to neutral donor-acceptor complexes, while the potentials difference between $\mathrm{TCNQF}_{2}$ and the immobilized TTF units falls in line with the coexistence of neutral and ionic charge-transfer complexes. The XPS measurements strongly support the formation of charge-tranfser complexes organized as a 2D arrangement with variable degree of charge transfer. In the $\mathrm{TTF}_{-} \mathrm{C}_{10}$ monolayer exposed to $\mathrm{TCNQF}_{4}$, the S2p signal clearly shows that all the TTF moieties are under the radical cation form, interacting with negatively charged $\mathrm{TCNQF}_{4}$ as identified in the corresponding N1s spectrum. 
These latter anionic species account for $80 \%$ of the detected $\mathrm{TCNQF}_{4}$, showing that an excess of neutral $\mathrm{TCNQF}_{4}$ that are not strongly interacting with the immobilized TTF radical cations are also present in the layer (see table 3 and discussion below). In the TTF- $\mathrm{C}_{10}$ monolayer exposed to $\mathrm{TCNQF}_{2}, \mathrm{~S} 2 \mathrm{p}$ signal does not allow to quantify confidently the two kind of TTF species (neutral and radical cation species) because the XPS resolution cannot mitigate the strong overlapping of these two signals. However, analysis of the N1s signal shows that $40 \%$ anionic and $60 \%$ neutral $\mathrm{TCNQF}_{2}$ species co-exist in the layer, supporting the formation of mixed neutral and ionic complexes.

Because of the fluorine contamination of the samples, only the N/S ratio was further considered to study more quantitatively the surface composition of the immobilized complexes. It is noticeable that the experimental ratio agrees well the theoretical expected ones for the TTF- $\mathrm{C}_{10}$ monolayers before exposure to any of the TCNQ compounds. Different theoretical ratios were calculated in Table 3 depending on the stoichiometry of the donoracceptor complex. From comparison with the experimentally estimated ratio, it could be proposed that the immobilized TTF units form a complex with TCNQ or TCNQF 2 with a stoichiometry corresponding to one or two TTF for one TCNQ/TCNQF 2 while the chargetransfer complex TTF-TCNQF 4 involves one TTF for one or two $\mathrm{TCNQF}_{4}$. Obviously, some immobilized TTF units could be free of acceptor neighbors, especially in the case of TCNQ and $\mathrm{TCNQF}_{2}$, as reflect the experimental N/S ratios which are lower than the theoretical ones, whatever the proposed stoichiometries. Similarly, the lower N/S ratio obtained for complexes with $\mathrm{TCNQF}_{2}$ than that for complexes with TCNQ suggest that there are less $\mathrm{TCNQF}_{2}$ molecules interacting with the TTF units. 
Table 3. Experimental N/S Ratios Evaluated from XPS Data and Comparison with the Theoretical Ratios Calculated for Different Complex Stoichiometries TCNQ Derivatives over TTF-C 10

\begin{tabular}{|c|c|c|c|c|}
\hline $\mathbf{N} / \mathbf{S}$ & TTF-C 10 & $\begin{array}{c}\text { TCNQ/ } \\
\text { TTF-C }_{10}\end{array}$ & $\begin{array}{l}\text { TCNQF }_{2} / \\
\text { TTF-C }_{10}\end{array}$ & $\begin{array}{l}\mathrm{TCNQF}_{4} / \\
\text { TTF-C }_{10}\end{array}$ \\
\hline Experimental & $\begin{array}{c}0.38 \\
\text { (theor. 0.43) }\end{array}$ & 0.66 & 0.53 & 1.20 \\
\hline $1: 1$ & - & 1 & 1 & 1 \\
\hline $1: 2$ & - & 0.71 & 0.71 & 0.71 \\
\hline $2: 1$ & - & 1.57 & 1.57 & 1.57 \\
\hline
\end{tabular}

It is worth outlining that these results fall in line with the different blocking behaviors toward dopamine of the TTF- $\mathrm{C}_{10}$ monolayers exposed to the acceptors and with the decrease of the electrochemical activity of the layer. Thus, the strongest blocking behavior is observed for the TTF- $\mathrm{C}_{10}$ exposed to $\mathrm{TCNQF}_{4}$. If there is more than one $\mathrm{TCNQF}_{4}$ compounds around the TTF units, the resulting steric hindrance prevents the dopamine from accessing the carbon surface. The decrease of electroactivity of the layer through the ratio ip/ip $p_{\text {TTF }}$ could be considered as a quantification of the strength of the association between the immobilized TTF and the different acceptors in relation with the $2 \mathrm{D}$ organization probably driven by the ionic, neutral or mixed nature of the charge-transfer complexes.

\section{CONCLUSION}

Alkyl-TTF molecules $\left(\right.$ TTF- $\mathrm{C}_{\mathrm{n}}$ ) could be immobilized as highly robust monolayers on carbon surfaces through an electrografting method combined to a click chemistry coupling of TTF$\mathrm{C}_{\mathrm{n}}$-azide precursors. When the TTF monolayer is exposed to an acceptor like TCNQ, $\mathrm{TCNQF}_{2}$ or $\mathrm{TCNQF}_{4}$, donor-acceptor complexes are formed on the surface. The formation of the complexes lead to a considerable decrease of the voltammetric peak currents. UMEC measurements with original crystal samples unambiguously confirm that a strong reduction of electro-activity accompanies the formation of charge-transfer complexes. Interestingly, the 
complexation could be modulated by varying the alkyl chain lengths of the bridge or by varying the strength of the acceptor, and the peak current decrease constitutes a convenient tool to monitor this modulation. The TTF units attached to the surface with the shortest and less flexible bridge (TTF-C 3 ) are hardly sensitive to the variation of the acceptor strength in sharp contrast to TTF- $\mathrm{C}_{10}$ that also allow a more efficient complexation with a given acceptor. XPS measurements point to the formation of donor-acceptor complexes of different nature, according to the strength of the acceptor. Fully ionic charge-transfer complex is formed upon exposure of immobilized TTF to the more oxidizing $\mathrm{TCNQF}_{4}$, while a neutral complex is obtained from exposure to the less oxidizing TCNQ. The TTF monolayers exposed to the intermediate $\mathrm{TCNQF}_{2}$ yield neutral-ionic systems. Noticeably, these donor-acceptor interactions evidenced at the carbon surfaces fully mimic those described in the solid-state. This work gives a rare example of a system directly connected to an electrode surface incorporating donor-acceptor complexes with a fine control of the degree of charge transfer. The modulation of the acceptor' strength offers the possibility of crystal-like engineering at a conductive surface to afford integrated molecular conductors.

\section{ACKNOWLEDGMENTS}

J.J. thanks the Région Bretagne for financial support (461-ARED). The authors are grateful to Dr. D. Hauchard (Institut des Sciences Chimiques de Rennes) for his help in the UMEC experiments. Dr. O. Jeannin (Institut des Sciences Chimiques de Rennes) is thanked for the gift of $\mathrm{TCNQF}_{4}$ compound. J. Hamon (Institut des Matériaux de Nantes, Nantes, France) is thanked for his help in the X-ray photoelectron spectra experiments. Dr M. Fourmigué (Institut des Sciences Chimiques de Rennes) is warmly acknowledged for fruitful discussions. 


\begin{abstract}
ASSOCIATED CONTENT
Supporting Information .Synthetic procedures and compounds characterization, additional electrochemical experiments for TTF layers and ferrocenyl layers, details about UMEC preparation and additional CVs of crystals, XPS survey spectra and high resolution core level fitted spectra.
\end{abstract}

\title{
AUTHOR INFORMATION
}

*E-mail: corinne.lagrost@,univ-rennes1.fr. Phone +33223235940

\section{REFERENCES}

(1) Bendikov, M.; Wudl, F.; Perepichka, D. F. Tetrathiafulvalenes, Oligoacenenes, and Their Buckminsterfullerene Derivatives: The Brick and Mortar of Organic Electronics, Chem. Rev. 2004, 104, 4891-4946.

(2) Yamada, J.-i.; Akutsu, H; Nishikawa; H.; Kikuchi, K. New Trends in the Synthesis of $\pi-$ Electron Donors for Molecular Conductors and Superconductors, Chem. Rev. 2004, 104, $5057-5084$.

(3) Geiser, U.; Schlueter, J. A. Conducting Organic Radical Cation Salts with Organic and Organometallic Anions, Chem. Rev. 2004, 104, 5203-5242.

(4) Fourmigué, M.; Batail, P. Activation of Hydrogen- and Halogen-Bonding Interactions in Tetrathiafulvalene-Based Crystalline Molecular Conductors, Chem. Rev. 2004, 104, 53795418. 
(5) Enoki, T.; Miyazaki, A. Magnetic TTF-Based Charge-Transfer Complexes. Chem. Rev. 2004, 104, 5449-5478.

(6) Coronado, E.; Day, P. Magnetic Molecular Conductors. Chem. Rev. 2004, 104, 54195448.

(7) Jérôme, D. Organic Conductors: From Charge Density Wave TTF-TCNQ to Superconducting (TMTSF) ${ }_{2} \mathrm{PF}_{6}$. Chem. Rev. 2004, 104, 5565-5592.

(8) Alves, H; Molinari, A. S.; Xie, H.; Mopurgo, A. F. Metallic Conduction at Organic Charge-Transfer Interfaces. Nat. Mat. 2008, 7, 574-580.

(9)Takahashi, Y.; Hayakawa, K.; Takayama, K.; Yokokura, S.; Harada, J.; Hasegawa, H.; Inabe, T. Charge Conduction Properties at the Contact Interface between (Phtalocyaninato)nickel (II) and Electron Acceptor Single Crystal, Chem. Mater. 2014, 26, 993-998.

(10) Takahashi, Y.; Hayakawa, K.; Naito, T.; Inabe, T. What Happens at the Interface between TTF and TCNQ Crystals $(\mathrm{TTF}=$ Tetrathiafulvalene and TCNQ $=7,7,8,8$ Tetracyanoquinodimethane)? J.Phvs.Chem.C 2012, 116, 700-703.

(11) Talham, D. R. Conducting and Magnetic Langmuir-Blodgett Films. Chem.Rev. 2004, $104,5479-5502$.

(12) Perepichka, D. F.; Bryce, M. R.; Pearson, C.; Petty, M.C.; McInnes, E. J. L.; Zhao, J. P. A Covalent Tetrathiafulvalene-Tetracyanoquinodimethane Diad: Extremely Low HOMOLUMO Gap, Thermoexcited Electron Transfer, and High-Quality Langmuir-Blodgett Films. Angew. Chem. Int. Ed. 2003, 42, 4636-4639. 
(13) Yip, C. M.; Ward, M. D. Self-Assembled Monolayers with Charge-Transfer Groups: nMercaptoalkyl Tetrathiafulvalenecarboxylate on Gold. Langmuir 1994, 10, 549-556.

(14) Skulason, H.; Frisbie, C. D. Self-Assembled Monolayers with Charge-Transfer Functional Groups: Immobilization of the Electron Donor TMPD and the Electron Acceptor TCNQ, Langmuir 1998, 14, 5834-5840.

(15) Yuge, R.; Miyazaki, A.; Enoki , T.; Tamada, K.; Nakamura , F.; Hara. M. Fabrication of TTF-TCNQ Charge-Transfer Complex Self-Assembled Monolayers: Comparison between the Coadsorption Method and the Layer-by-Layer Adsorption Method. J. Phvs. Chem. B 2002, 106, 6894-6901.

(16) Pacsial, E. J.; Alexander, D.; Alvarado, R. J.; Tomasulo, M.; Raymo, F. M. Donor/Acceptor Interactions in Self-Assembled Monolayers and Their Consequences on Interfacial Electron Transfer. J.Phvs. Chem. B 2004, 108, 19307-19313.

(17) Howell, S.; Kuila, D.; Kasibhatla, B.; Kubiak, C. P.; Janes, D.; Reifenberger, R. Molecular Electrostatics of Conjugated Self-assembled Monolayers on Au(111) Using Electrostatic Force Microscopy. Langmuir 2002, 18, 5120-5125.

(18) Skulason, H.; Frisbie, C. D. Direct Detection by Atomic Force Microscopy of Single Bond Forces Associated with the Rupture of Discrete Charge-Transfer Complexes. J. Am. Chem. Soc. 2002, 124, 15125-15133.

(19) Kasibhatla, B. S. T.; Labonté, A. P.; Zahid, F.; Reifenberger, R. G.; Datta, S.; Kubiak, C. P. Reversibly Altering Electronic Conduction through a Single Molecule by a Chemical Binding Event. J.Phvs.Chem.B 2003, 107, 12378-12383. 
(20) Goeltz, J. C.; Kubiak, C. P. Mixed Valence Self-assembled Monolayers: Electrostatic Polarizabilities of the Mixed Valence States. J. Phys. Chem. C 2008, 112, 8114-8116.

(21) Ferraris, J.; Cowan, D. O.; Walatka, V.; Perlstein, J. H. Electron Transfer in a New Highly Conducting Donor-Acceptor Complex. J.Am. Chem. Soc. 1973, 95, 948-949.

(22) Aviram, A.; Ratner, M. A. Molecular Rectifier. Chem. Phvs. Lett. 1974, 29, 277-283.

(23) Metzger, R. Unimolecular Electrical Rectifiers. Chem Rev 2003, 103, 3803-3834

(24) Yokota, Y.; Miyazaki, A.; Fukui, K. I.; Enoki, T.; Tamada, K.; Hara, M. Dynamic and Collective Electrochemical Responses of Tetrathiafulvalene Derivative Self-Assembled Monolayers. J.Phys. Chem. B 2006, 110, 20401-20408.

(25) Kim, J.-S.; Lee, S.-K.; Lee, H.-J.; Noh, D.-Y. A Charge-transfer Phenomenon between 2,3,5,6-Tetrafluoro-7,7,8,8-tetracyanoquinodimethane ( $\left.\mathrm{F}_{4} \mathrm{TCNQ}\right)$ and a Tetrathiafulvalenebased Self-assembled Monolayer Using an Indium-Tin Oxide Electrode. Bull.Korean Chem. Soc. 2010, 31, 1415-1418.

(26) Blanchard, P. Y.; Alévêque, O.; Boisard, S.; Gautier, C.; El-Ghayoury, A.; Le Derf, F.; Breton, T.; Levillain, E. Intermolecular Interactions in Self-assembled Monolayers of Tetrathiafulvalene Derivatives. Phvs. Chem. Chem. Phvs. 2011, 13, 2118-2120.

(27) Pinson, J.; Podvorica, F. Attachment of Organic Layers to Conductive or Semiconductive Surfaces by Reduction of Diazonium Salts. Chem. Soc. Rev. 2005, 34, 429439.

(28) Kaminska, I.; Barras, A.; Coffinier, Y.; Lisowski, W.; Roy, S.; Niedziolka-Jonsson, J.; Woisel, P.; Lyskawa, J.; Opallo, M.; Siriwardena, A.; et al. Preparation of a Responsive 
Carbohydrate-Coated Biointerface Based on Graphene/Azido-Terminated Tetrathiafulvalene Nanohybrid Material. Appl. Mater. Interfaces 2012, 4, 5386-5393.

(29) Leroux, Y. R.; Fei, H.; Noël, J.-M.; Roux, C.; Hapiot, P. Efficient Covalent Modification of a Carbon Surface: Use of a Silyl Protecting Group To Form an Active Monolayer. J.Am.Chem. Soc. 2010, 132, 14039-14041.

(30) Leroux Y. R.; Hapiot, P. Nanostructured Monolayers on Carbon Substrates Prepared by Electrografting of Protected Aryldiazonium Salts. Chem.Mater. 2013, 25, 489-495.

(31) Anderson, S. Phenylene Ethynylene Pentamers for Organic Electroluminescence. Chem.Eur.J. 2001, 7, 4706-4714.

(32) Wheland, R. C. and Martin, E. L. Synthesis of Substituted 7,7,8,8Tetracyanoquinodimethanes. J. Org. Chem. 1975, 40, No.21, 3101-3109.

(33) Lorcy, D.; Shin, K.-S.; Guerro, M.; Simonet, J. $\pi$-Donor Layer Coverage onto Glassy Carbon by Electrochemical Means. Reduction of $\omega$-Iodoalkyl-Tetrathiafulvalenes Electrochimica Acta, 2013, 89, 784-791.

(34) Cachet-Vivier, C.; Keddam, M.; Vivier, V.; Yu, L T. Development of Cavity Mmicroelectrode Devices and their Uses in Various Research Fields. J.Electroanal. Chem. 2013, $688,12-19$.

(35) Microélectrode à cavité - Principe, Développement et Applications pour l'Etude de la Réactivité de Matériaux Insoluble; V. Vivier (Ed.), Publications de l'Université de SaintEtienne: Saint-Etienne, 2009. 
(36) Savéant, J.-M. Elements of Molecular and Biomolecular Electrochemistry; WileyInterscience, Hoboken, 2006.

(37) Yzambart, G.; Fabre, B.; Lorcy, D. Multiredox Tetrathiafulvalene - Modified OxideFree Hydrogen-Terminated Si(100) Surfaces. Langmuir 2012, 28, 3453-3459.

(38) Paxton, W. F.; Kleinman, S. L.; Basuray, A. N.; Stoddart, J. F.; Van Duyne, R. P. Surface-Enhanced Raman Spectroelectrochemistry of TTF-Modified Self-Assembled Monolayers L.Phvs. Chem.Lett. 2011, 2, 1145-1149.

(39) Honeychurch, M. J.; Rechnitz, G. A. Voltammetry of Adsorbed Molecules. Part 1: Reversible Redox Systems. Electroanalvsis 1998, 10, 285-293.

(40) Lee, L. Y. S.; Sutherland, T. C.; Rucareanu, S.; Lennox, R. B. Ferrocenylalkylthiolates as a Probe of Heterogeneity in Binary Self-Assembled Monolayers on Gold. Langmuir 2006, $22,4438-4444$.

(41) Jaeger, C. D.; Bard, A. J. Electrochemical Behavior of TetrathiafulvaleneTetracyanoquinodimethane Electrodes in Aqueous Media, J. Am. Chem. Soc. 1979, 101, $1690-1699$

(42) DuVall, S. H.; McCreery, R. L. Control of Catechol and Hydroquinone ElectronTransfer Kinetics on Native and Modified Glassy Carbon Electrodes. Anal. Chem. 1999, 71, 4594-4602.

(43) DuVall, S. H.; McCreery, R. L. Self-catalysis by Catechols and Quinones during Heterogeneous Electron Transfer at Carbon Electrodes. J. Am. Chem. Soc. 2000, 122, 67596764. 
(44) Lhenry, S.; Leroux, Y.R.; Hapiot, P. Use of Catechol As Selective Redox Mediator in Scanning Electrochemical Microscopy Investigations. Anal. Chem. 2012, 84, 7518-7524.

(45) Amatore, C.; Savéant, J.-M.; Tessier, D. Charge transfer at partially blocked surfaces: A model for the case of microscopic active and inactive sites. LElectroanal Chem. 1983, $147,39-51$.

(46) Compton, R.G.; Menshykau, D. Electrodes Modified with Electroinactive Layers: Distinguishing Through-Film Transport from Pinhole (Pore) Diffusion. Langmuir 2009, 25, 2519-2529.

(47) Qin, G.; Santos, C.; Zhang, W.; Li, Y.; Kumar, A.; Erasquin, U. J.; Liu, K.; Muradov, P.; Trautner, B. W.; Cai, C. Biofunctionalization on Alkylated Silicon Substrate Surfaces via “Click” Chemistry. J.Am.Chem. Soc. 2010, 132, 16432-16441.

(48) Tengstedt, C.; Unge, M.; de Jong, M. P.; Stafström, S.; Salaneck, W. R.; Fahlman, M. Coulomb Interactions in Rubidium-Doped Tetracyanoethylene: A Model System for Organometallic Magnets. Phvs. Rev. B 2004, 69, 165208.

(49) Bellitto, C.; Bonamico, M.; Fares, V.; Imperatori, P.; Patrizio, S. Tetrathiafulvalenium salts of planar Pt, Pd, and $\mathrm{Cu}$ 1,2-dithio-oxalato-S,S[',’] anions. Synthesis, Chemistry and Molecular Structures of bis(tetrathiafulvalenium) bis(1,2-dithio-oxalato-S,S[',’])palladate(II), $[\mathrm{ttf}]_{2}\left[\mathrm{Pd}\left(\mathrm{S}_{2} \mathrm{C}_{2} \mathrm{O}_{2}\right)_{2}\right]$, and of bis(tetrathiafulvalenium)tetrathiafulvalene bis(1,2-dithio-oxalato$\left.\mathrm{S}, \mathrm{S}\left[{ }^{6}, "\right]\right)$ platinate(II), [ttf $]_{3}\left[\mathrm{Pt}\left(\mathrm{S}_{2} \mathrm{C}_{2} \mathrm{O}_{2}\right)_{2}\right] . J$. Chem. Soc., Dalton Trans. 1989, 4, 719-727.

(50) Choudhury, D.; Das, B.; Sarma, D. D.; Rao, C. N. R. XPS Evidence for Molecular Charge-Transfer Doping of Graphene. Chem. Phvs. Lett. 2010, 497, 66-69. 
(51) Lieffrig, J.; Jeannin, O.; Frąckowiak, A.; Olejniczak, I.; Świetlik, R.; Dahaoui, S.; Aubert, E.; Espinosa, E.; Auban-Senzier, P.; Fourmigué, M. Charge-Assisted Halogen Bonding: Donor-Acceptor Complexes with Variable Ionicity Chem.Eur.J. 2013, 19, 1480414813.

(52) Torrance, J. B.; Vazquez, J. E.; Mayerle, J. J.; Lee, V. Y. Discovery of a Neutral-toIonic Phase Transition in Organic Materials. Phvs. Rev. Lett. 1981, 46, 253-257.

(53) Lieffrig, J.; Jeannin, O.; Guizouarn, T.; Auban-Senzier, P.; Fourmigué, M. Competition between the $\mathrm{C}-\mathrm{H} \cdots \mathrm{N}$ Hydrogen Bond and $\mathrm{C}-\mathrm{I} \cdots \mathrm{N}$ Halogen Bond in TCNQFn $(\mathrm{n}=0,2,4)$ Salts with Variable Charge Transfer. Crvstal Growth \& Desion 2012, 12, 4248-4257.

(54) Iyoda, M.; Suzuki, H.; Sasaki, S.; Yoshino, H.; Kikuchi, K.; Saito, K.; Ikemoto, I.; Matsuyama, H.; Mori, T. Charge-Transfer Complex and Radical Cation salt of a New Donor EDT-TTFCl ${ }_{2}$ : Unique Conductivities and Crystal Structures L_Mater. Chem. 1996, 6, 501503.

\section{GRAPHICAL ABSTRACT}




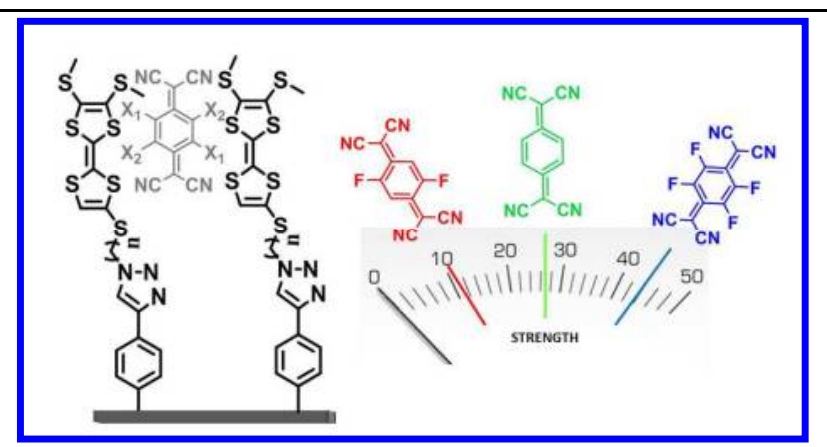

1

2

3

4

5

6

10

11

12

13

14

15

16

17

18

19

20

21

22

23

24

25

26

27

28

29

30

31

32

33

34

35

36

37

38

39

40

41

42

43

44

45

46

47

48

49

50

51

52

53

54

55

56

57

58

59

60 